\title{
Discussion on Enlightenment of City Memory for Environmental Design of Traditional Blocks
}

\author{
Haijun Lv \\ Huanghe Science and Technology College \\ Zhengzhou, China
}

\begin{abstract}
Every city has it own unique city memory, which is the manifestation of urban creativity and urban spirit. As the carrier of city memory, traditional blocks play a role in the city that changes from the original pure place of residence to the cultural core of the city and become places where the spirit and soul of blocks lie. Traditional blocks use its unique sense of place to present the inside information and connotation of a city. Its quality characteristic relates to the integral image and vitality of city. However, in recent years, the relatively fast speed and process of our urban renewal has brought various problems for the protection and renewal of historical blocks. It becomes an inevitable urgent task in front of us that how to deal with the complicated contradiction and achieve balance between economic development and revitalization of historical blocks, and explore the mode of protection and renewal of historical blocks that suit each regional characteristic.
\end{abstract}

Keywords - city memory, traditional blocks, environmental design

\section{INTRODUCTION}

Every city has its own unique city memory, which is the manifestation of urban creativity and urban spirit. Looking from a deeper level, city memory reflects the ideal, belief, system, ethics and values of city and society. City memory is the reflection of people as well as society. Human and society have close relationships with city memory. City memory tells us who we are, where we come from and where we will go.

People place hope and ideal when they live in city. Using history to enhance the taste of city can meet the needs of social life of contemporary people. Historical architecture and space environment witness the development of city and society. If there are no architectures and urban space that are remained in history, the history will not be as natural as though it were living. If we lose city memory, our life will not be colorful and city will lose the history that makes us proud. And the understanding of people for city development will lack the evidence of form and spiritual basis.

City memory represents understandings of people for the history and future of urban space and environment and also represents the ideal of city in this age, as well as reflects the value pursuit of country, nation, city and people. City memory is the milestone of urban history. The evolution of city memory represents the progress and prosperity of city. City memory must be regional and cannot be copied. Except for amusement parks, we should not copy architectures such as the Eiffel Tower in Paris, the Saint Peter' $s$ Basilica in Rome and the White House in Washington.

Therefore, constructing city memory is to protect urban history and culture and our pursuit for ideal city. It has important enlightenment for the construction of modern cities in our country.

\section{PROPOSAL OF THE CONCEPT OF CITY MEMORY}

At present, city memory has not formed specific and fixed expression. People often use it as "the memory of a city" and "historical memory of a city" . Besides, in use, it can refer to "object" as well as "thing" and even people in the past. Therefore, it appears specious chaotic situation. It is necessary for us to tease the accurate concept of city memory.

The concept of city memory should include three basic aspects of urban form, function and meaning. City memory is the integral historical cognition of the meaning and forming process of urban space and environment. The expression of "forming process" has summarized the influences and dynamic evolution status produced by many aspects such as urban form and function for urban environmental significance.

City memory is located in urban space and environment and reflected in people's memory and also people's cognition for the meaning of urban space and environment. Meanwhile, because in the process of urban development, people continuously and dynamically reconstruct urban space and environment, city memory is in the situation of constant change and development instead of being changeless. People's reconstruction activities that can influence city memory make the forming of city memory cannot break away from people's understanding for environmental significance, at the same time, it continuously adds new contents. If these new contents separate themselves from people's understandings in the past for environmental significance, it will make city memory happen "dislocation" of memory, even "memory loss". The "dislocation" of memory means that new contents in city memory break away from the principles insisted by the meaning of urban space and environment in historical development all along. "Memory loss" means that these new contents completely break away from the continuity of evolution of 
environmental significance, and then make city memory cannot keep in touch with the significance of environment in the past.

\section{EMBARRASSING SITUATION OF TRADITIONAL BLOCKS IN THE PROCESS OF MODERNIZATION}

Nowadays, with rapid development of urban economy and the increasingly tense land use, as one of the forms of urban centripetal growth, the renewal and reconstruction of traditional blocks have become important ways to effectively make use of urban land. In the overwhelming strategy of urban planning, the large-scale demolition and reconstruction of traditional blocks have become universal phenomenon of urban renewal in big cities. In order to pursue high profits, people remove a great number of traditional blocks that have certain cultural value and can embody the development of urban history, and use large office building, residence and business center to replace them. It leads to severe cultural crisis and "memory loss" of city under economic impact. The carrier of city memory that truly records the historical development and evolution of urban space will gradually disappear. The overwhelming strategy of renewal and reconstruction of city is placed in an awkward position in the process of economic development. This kind of embarrassment mainly comes from:

\section{A. The FIrst is Contradiction between Cultural Protection and Economic Input.}

On the whole, this kind of block can reflect complex city texture and neighborhood relationships in society, but it is not listed as object of protection. Most buildings can be demolished and reconstructed if people control the volume according to the rules. They are different from buildings of preservation of cultural relics. The historical importance of buildings of preservation of cultural relics determines means that the country must protect them at any cost. While in reality, it is indeed difficult for traditional blocks to find reasons of existence and development economically. The investment in protection of traditional blocks must have certain returns. It is the rule that any people cannot resist under the condition of marketing economy.

\section{B. The Second is Contradiction between "High Land Price" and "Low Floor Area Ratio".}

This kind of blocks is often located in city center. After our country implement the land compensated use system, because the sections in city center have "advantage in time" and "advantage of opportunity", the land prices of them increase correspondingly. The original industries with low additional value will be transferred to urban fringe successively. The distribution of land price presents the situation that the center area reaches the zenith and then decrease outward progressively in turn, which directly cause the space reorganization of functional land in city. Because of the violent increase of land price, traditional blocks located in urban center are involved in this aggressive space reorganization. However, this kind of block always has low floor area ratio. If people reconstruct it by maintaining the original style, the land cost will account for an extremely high proportion. It makes the floor area ratio and layers of the building greatly increase after reconstruction. At the same time, it is difficult to preserve the style and features of traditional blocks in today when urban economy develops rapidly.

Therefore, in order to reserve the historical and cultural value of traditional blocks as well as meet the law of economic development, it is urgent for us to deeply discuss more appropriate concept of renewal and reconstruction for traditional blocks.

\section{ENLIGHTENMENT OF CITY MEMORY FOR ENVIRONMENTAL DESIGN OF TRADITIONAL BLOCKS}

The ideology of "changing the old practice and creating new situation" is deep-rooted in our country. The establishment and deepening of the concept of historical and cultural protection have experienced a historical process. People often regard it as a kind of "progress" by using new things to replace the old. For example, Xiang Yu burned Xianyang city in Qing dynasty, which appeared the situation that "the fire didn't go out for three months"; the attack on Four Olds: old thoughts, old culture, old habits, old customs, demolish city wall and ruin temples in the "Cultural Revolution" in contemporary era. These behaviors are under the influence of this ideology. Today when people look back to the past affairs, they feel so sorry for these, because these precious historical and cultural wealth have already gone forever. In recent years, the destruction of "reconstruction of old city" for traditional blocks is also amazing. In more than ten years of upsurge of urban construction, quite a few memories of the city completely vanish along with the dust caused by bulldozers. This kind of examples are too numerous to mention. For example, when World Expo is held in Kunming, people demolish and reconstruct in the old city, which make the historical Qingyun Street disappear; the Er Fang Qi Xiang in Fuzhou also disappear under the destructive construction of businessmen from Hong Kong. No wonder Kihara Keiyoshi defines in his book of Historical Environment that the period of high economic growth after the 1850 s is the period when historical environment suffers from the most serious destruction. It outdistances the destruction of the Second World War.

Nowadays, when people put emphasis on sustainable development, traditional blocks in city increasingly present the characteristic -rareness just as other resources that are constantly consumed and faced with shortage.

City memory enlightens us to take traditional block as a kind of resource and establish a kind of new overall concept of protection and development of urban history and culture. The development of city memory tells us that city memory and buildings and space environment of city are always continuous and replaceable evolution in historical development of city. It makes traditional blocks have everlasting historical and cultural value. And this kind of value is multivariate. Except for values that can be measured by currency such as land value and property values, it has more values that cannot be measured by money such as emotional value and cultural value. At the same time, city 
memory system expresses historical site in the city and the interactive relationship between original space and new buildings formed in the process of renewal and reconstruction, and can make these values continuously expand and add value. In the process of increment of value, city memory plays the role of "enzyme" . Under its effects, the current situation of city connects and recombines with the history and forms a kind of new integral relationship.

Under the concept of emphasizing time dimension, city memory stresses the sustainable development of renewal and reconstruction of traditional blocks. It thinks that once historical sites in city have relationships with the surrounding environment, it significance is enlarged, which make traditional blocks become not only a kind of resources but also a kind of reproducible resources. As the carrier of city memory, traditional blocks play a role in the city that change from the original pure place of residence to places of culture core of community in the city, and become the place where the spirit and soul of community lie. In urban construction, large-scale buildings with indifferent temperament have swallowed traditional residence with rich city memory. Cold new buildings cannot meet the increasingly strong nostalgic feelings of people after the material level is improved. As a kind of irreversible development tendency, this kind of spiritual requirement makes city memory gradually become a kind of "latent capital" to drive the promotion of taste and value of development of surrounding areas.

Take Xintiandi as an example, it locates in the surrounding region of the site of the First Conference of the CPC in Luwan district in Shanghai. It is the real estate project developed by Ryan Hong Kong Real Estate Company Limited. It keeps a large area of pattern of lanes, especially devotes greater efforts and funds than building modern architecture to reserve and repair the appearance of facade, details and spatial pattern of lanes of Shikumen buildings that have obvious memory characteristics, make modifications for the interior building, in order to adapt to forms in modern life such as handle official business, commerce, catering and recreation. On the land of Beili of Xintiandi square with the area of less than two hectares, there were various criss-cross lanes built on it originally and the land was densely covered by old houses with an area of about 30,000 square meters. The earliest house was built in 1911 and the latest house was built in 1933. Most of them do not connect. Some can directly reach the gate of the lanes, while people can reach some houses via other lanes. After we firstly figure out the relationships between them and "take out" some spaces for people to take activities and breathe in the dense houses, and reserve symbolic buildings and parts with memory characteristics in this space, then vicissitudes and the modern, nostalgia and fashion, history and reality intersect here. British architect Pablo Vaggione said when he was interviewed by reporter of New Weekly, "In reality, restoring the old as the old is the process of recovering to its original appearance in assumption". Therefore, the valuable point of section in Xintiandi lies in that it researches and explores urban life experience of people in modern times, emphasizes the integration of historical style and experience in real life, and pursues a kind of "continuous, gradual, complex and exquisite change".

The development of section in Xintiandi successfully attracts extensive attentions from all sectors of society. Some criticize it while some give affirmation. Most criticisms focus on aspects that the protection of traditional architecture is incomprehensive and halfway, while good reputations focus on that it embodies "nostalgic lifestyle" and "enduring charm". In the development of Xintiandi, people actively cultivate and derive commercial culture, pay attention to improve cultural taste of the region and establish a new lifestyle through understanding the significance of space and environment in the past. The establishment of this kind of concept derives from the characteristics of historical development of its surrounding environment. Xintiandi locates in eastern section of Huaihaizhong Road and this place has become the auxiliary area of Shanghai CBD in historical development of Shanghai. This place leaves an elegant impression in the mind of people in the past, mainly because it has very strong and the most developed urban industry and commercial features at that time and it is also city memory that leads the fashionable commercial life forms. Through combination between reality and history, the exploitation positioning of Xintiandi has found powerful support from the development of significance of space and environment in this region.

\section{CONCLUSION}

Through this way, city memory has become a kind of capital and involved in the landscape renovation of traditional blocks, not only improves the value of material capital, but also becomes an organic component of integral space environment.

\section{REFERENCES}

[1] Zhang Song. Introduction to Historical City Protection-Integral Method for the Protection of Cultural Heritage and Historical Environment [M], Shanghai: Shanghai Science and Technology Press, 2001

[2] Shan Jixiang. Movement from "Functional City" to "Cultural City" [M], Tianjin University Press, 2007

[3] Wang Hao, Tang Xiaolan, Sun Xinwang, Wang Jing. Characteristics and Integration of Urban Landscape [M], China Forestry Publishing House, 2008 